\title{
Impact of left atrial volume, sphericity and fibrosis on the outcome of catheter ablation for atrial fibrillation
}

Dennis W. den Uijl, MD, PhD, ${ }^{1-2}$ Nuno Cabanelas, MD, ${ }^{1-2}$ Eva M. Benito, MD, ${ }^{1-2}$ Rosa Figueras, PhD, ${ }^{1-2}$ Francisco Alarcón, BSc, ${ }^{1-2}$ Roger Borràs, BSc, ${ }^{1-2}$ Susanna Prat, MD, PhD, ${ }^{1-2}$ Eduard Guasch, MD, PhD, ${ }^{1-2-3}$ Rosario Perea, MD, PhD, ${ }^{1-2-3}$ Marta Sitges, MD, PhD, ${ }^{1-2-3}$ Josep Brugada, MD, PhD, ${ }^{1-2-3}$ Antonio Berruezo, MD, PhD, ${ }^{1-2-3}$ Lluís Mont, MD, $\mathrm{PhD}^{1-2-3}$

${ }^{1}$ Institut Clínic Cardiovascular, Hospital Clínic, Universitat de Barcelona. ${ }^{2}$ Institut d'Investigacions Biomèdiques August Pi i Sunyer (IDIBAPS). ${ }^{3}$ CIBERCV, Instituto de Salud Carlos III.

DWdU and NC have contributed equally to the paper.

Short title: LA volume, sphericity and fibrosis in AF ablation

\section{Address for correspondence}

Dr. Lluís Mont, MD, PhD

Department Cardiology, Arrhythmia Section

Thorax Institute, Hospital Clinic Barcelona

C/Villarroel 170

08036 Barcelona, Spain

E-mail: Imont@clinic.ub.es

This work was supported by the European Union's Horizon 2020 research and innovation programme under grant agreement No 633196 (CATCH ME project); Instituto de Salud Carlos III (ISCIII), PI16/00703; Instituto de

This article has been accepted for publication and undergone full peer review but has not been through the copyediting, typesetting, pagination and proofreading process, which may lead to differences between this version and the Version of Record. Please cite this article as doi: 10.1111/jce.13482.

This article is protected by copyright. All rights reserved. 
Salud Carlos III (ISCIII), PI16/00435; Instituto de Salud Carlos III (ISCIII), CIBERCV16: CB16/11/00354; Fundació la Marató de TV3. 20152730. CERCA Programme / Generalitat de Catalunya.

L. Mont., J. Brugada. and A. Berruezo. are shareholders of Galgo Medical Company. Other authors: No disclosures.

\section{ABSTRACT}

Introduction: To investigate the relation between left atrial (LA) volume, sphericity and fibrotic content derived from contrast-enhanced cardiac magnetic resonance imaging (CE-CMR) and their impact on the outcome of catheter ablation for atrial fibrillation (AF).

Methods and results: In 83 patients undergoing catheter ablation for AF, CE-CMR was used to assess LA volume, sphericity and fibrosis. There was a significant correlation between LA volume and sphericity $(R=0.535, p<0.001)$ and between $L A$ volume and fibrosis $(R=0.241$, $p=0.029)$. Multivariate analyses demonstrated that LA volume was the strongest independent predictor of AF recurrence after catheter ablation $(1.019, p=0.018)$.

Conclusion: Left atrial volume, sphericity and fibrosis were closely related, however LA volume was the strongest predictor of AF recurrence after catheter ablation.

Keywords: Cardiac magnetic resonance; atrial fibrillation ablation, atrial sphericity, left atrial volume, atrial fibrosis.

\section{INTRODUCTION}

Pulmonary vein isolation is a potentially curative treatment option for patients with atrial fibrillation (AF). ${ }^{1}$ However, despite the many technological developments in recent years, the success rate of these procedures remains to be wanting. ${ }^{2}$ Identifying patients that will benefit from this treatment is imperative to improve its success rate. Moreover, identification of 
patients with a low likelihood to benefit from pulmonary vein isolation alone allows the electrophysiologist to plan a more comprehensive ablation approach in order to improve the outcome.

Left atrial (LA) remodelling is thought to limit the efficacy of catheter ablation for AF: the more diseased the atria are, the less likely a patients is to benefit. ${ }^{3,4}$ Traditionally, the degree of atrial remodelling was assessed by measurement of the LA diameter. ${ }^{5,6}$ Recent developments in the field of contrast enhanced cardiac magnetic resonance (CE-CMR) allow a more comprehensive characterization of the LA by identification and quantification of LA fibrosis and precise measurement of the LA volume and assessment of the LA shape/sphericity. ${ }^{7-9}$

The aim of the present study is to investigate the relation between LA volume, LA sphericity and LA fibrosis in patients with $A F$, and to examine their relative prognostic impact on the outcome of catheter ablation for AF.

\section{METHODS}

\section{Patient population and study protocol}

The current population comprises a cohort of consecutive patients that underwent CE-CMR prior to a first catheter ablation for $\mathrm{AF}$ in our institution. Atrial fibrillation was refractory to at least one antiarrhythmic drug in all patients, according to the current expert consensus statement document. The CE-CMR data was collected prospectively as part of the preprocedural evaluation and was retrospectively analyzed to determine LA volume, sphericity and fibrotic content. The prognostic impact of these parameters on the outcome of catheter ablation for AF was studied. The study protocol was approved by our hospital's ethics committee, and written informed consent was obtained from all patients. 


\section{Contrast Enhanced Cardiac Magnetic Resonance}

Image acquisition

The acquisition protocol has been reported previously. ${ }^{8}$ In brief, all studies were obtained on a 3-Tesla scanner (Magnetom Trio, Siemens Healthcare, Erlangen, Germany) and a dedicated 32-channel cardiac coil. The scan was acquired 20 minutes after injection of an intravenous bolus of $0.2 \mathrm{mmol} / \mathrm{kg}$ gadobutrol (Gadovist, Bayer Schering Pharma AG, Berlin, Germany) using a free-breathing 3D navigator and ECG-gated inversion-recovery gradienteco sequence applied in the axial orientation. The voxel size was $1.25 \times 1.25 \times 2.5 \mathrm{~mm}$. Repetition time/echo time was 2.3/1.4 ms; flip angle, 110; bandwidth, $460 \mathrm{~Hz} /$ pixel; inversion time (TI) 280 to $380 \mathrm{~ms}$; and parallel imaging with GRAPPA technique, with reference lines of $R=2$ and 72 . A TI scout sequence was used to nullify the left ventricular myocardial signal and determine optimal TI. Typical scan time for a LGE-CMR sequence was 15 minutes (range 11-18), depending on heart rate and breathing patterns.

Post-processing

After data acquisition, all CE-CMR data were exported to the ADAS ${ }^{\circledR}$ program (GALGO Medical, Barcelona, Catalunya, Spain) for off-line post-processing. A typical example of the post-processing is shown in Figure 1. First, endocardial and epicardial contours of the LA were semi-automatically traced in each axial image. Second, in order to minimize endocardial and epicardial segmentation artefacts, $\mathrm{ADAS}^{\circledR}$ constructed a mid-myocardial layer (50\% thickness) into a 3D shell of the LA. The mitral valve leaflets were used as landmarks to separate the LA from the left ventricle and the LA appendage and the pulmonary veins were excluded at their ostia, defined as the site of reflection of these 
structures with the surrounding LA wall. Next, the signal intensity of the LA wall was normalized to the blood pool intensity by calculating the Image Intensity Ratio (IIR) and projecting the color-coded values onto the 3D mid-myocardial shell of the LA. Based on previous work of our group, ${ }^{8}$ LA tissue with an IIR $>1.20$ was considered as fibrotic tissue. $\mathrm{ADAS}^{\circledR}$ automatically calculated the size of the fibrotic areas as well as the percentage of the LA wall that was fibrotic. The degree of LA fibrosis was classified according to the Utah Staging System (UTAH I: $\leq 5 \%$ LA wall enhancement, UTAH II: $>5 \%$ and $\leq 20 \%$, UTAH III: $>20 \%$ and $\leq 35 \%$, UTAH IV: $>35 \%)^{9}$

Finally, the software calculated the LA volume and LA sphericity from the 3D shell. The LA sphericity is a measure for the difference in shape between the actual LA and a theoretical sphere-shaped LA. ${ }^{7}$ The radius of this theoretical sphere equals the average radius $(A R)$ between the endocardial borders and the centre of mass of the actual LA. To determine the LA sphericity, the AR and the standard deviation of the AR are used to calculate the coefficient of variation (AR standard deviation/AR). Successively, LA sphericity is calculated using the following formula [(1 - coefficient of variation $) \times 100]$. All analyses were performed blinded to the clinical parameters.

A perfect sphere-shaped LA has a sphericity value of 100 , with lower values for those atria adopting non-spherical contours. It is thought that the remodelling process involves a progressive change in atrial morphology that evolves from discoid-shaped to sphere-shaped, thereby progressively increasing the sphericity value. Previous work by our group has shown that a high LA sphericity value is associated with a higher risk for AF recurrence after ablation and improves the performance of the CHADS-VASc score in stroke prediction. ${ }^{7,10}$

\section{Catheter ablation}

This article is protected by copyright. All rights reserved. 
All ablation procedures were performed under deep sedation. After venous access through the femoral vein, a double transseptal puncture was performed to acquire access to the LA. A bolus of heparin (5000-6000 IU, according to patient weight) was then administered, as well as an additional bolus, to maintain an acitivated clotting time of $250-300 \mathrm{~s}$. A circular mapping catheter (LASSO ${ }^{\circledR}$, Biosense Webster, Daimond Bar, CA, USA) was introduced inside the LA to assess pulmonary vein conduction.

Catheter ablation was either performed using radiofrequency or a cryoballoon. Both procedures have been described previously. ${ }^{7,11}$ In brief, during the procedures with a cryoballoon, the catheter (Arctic Front, Medtronic, Minneapolis, MN, USA) was positioned inside each pulmonary vein antrum selectively using fluoroscopy. After confirmation of adequate occlusion, the balloon was filled with a liquid refrigerant during a 5-minute application. After application, pulmonary vein conduction was checked and additional applications were delivered until pulmonary vein isolation was confirmed.

During radiofrequency catheter ablation, two circular lesions were created around the ipsilateral left and right pulmonary vein ostia using a non-fluoroscopic mapping system (CARTO $3^{\text {TM }}$, Biosense Webster). Radiofrequency current was applied by a $3.5 \mathrm{~mm}$ openirrigation catheter (NaviStar ${ }^{\mathrm{TM}}$, Biosense Webster) at a target temperature of $45^{\circ} \mathrm{C}$ and a maximum output of $40 \mathrm{~W}$ until pulmonary vein isolation was confirmed. In order to reduce the risk of oesophageal complications, power was reduced to $35 \mathrm{~W}$ in the posterior wall and RF application was limited to 10 to 20 seconds per point. Additional ablation lesions (e.g., linear lesions or fractionated area ablation [CFAE]) were created at the discretion of the operator. 
The procedural endpoint for both techniques was pulmonary vein isolation demonstrated by bidirectional block on the circular mapping catheter or entrance block when local capture inside the pulmonary vein could not be confirmed.

\section{Follow-up}

After ablation, all patients were evaluated on a regular basis at the outpatient clinic $(1,3,6$ and 12 months). ECG recordings were acquired each visit as well as 24-hour ECG Holter monitoring. In addition to these routine visits, patients were encouraged to immediately obtain an ECG registration when experiencing palpitations. After a blanking period of 3 months, recurrence of $A F$ was defined as any recording of $A F$ on ECG or an episode longer than $30 \mathrm{~s}$ on 24-hour ECG Holter registration. ${ }^{1}$

\section{Statistical analyses}

All variables were tested for a normal distribution with the Shapiro-Wilk test. Normally distributed continuous variables are represented as mean \pm SD and non-normally distributed continuous variables are represented as median (Interquartile Range [IQR]). Categorical variables are presented as number (percentage). Statistical comparisons for continuous variables were performed with the Student $t$ test or with the Mann-Whitney $U$ test as appropriate. Statistical comparisons for categorical variables were performed with the Chisquare test. Univariable Cox proportional hazard analyses were performed to investigate the impact of LA volume, sphericity and fibrotic content on the recurrence of AF after ablation. The variables with a $\mathrm{P}<0.1$ in the univariable analysis were included in the multivariable analysis. Multivariable analysis was performed using a backward Wald stepwise method (variables with $\mathrm{P}>0.1$ were removed from the model). For the multivariate analysis, we use 
the $\mathrm{P} / 10$ rule to avoid overfitting in the final model. Receiver operator characteristic curve analysis was performed to determine the optimal cut-off value for the strongest independent predictor to predict AF recurrence, based on the highest combined sensitivity and specificity. Furthermore, Kaplan-Meier plots were created and the log-rank test was performed to test the difference in AF recurrence after ablation using these cut-off values. All statistical analyses were performed with SPSS software (version 23.0, IBM Corporation, Armonk, NY, USA). A value of $P<0.05$ was considered statistically significant.

\section{RESULTS}

A total of 83 patients [64 men (77\%), mean age $55.8 \pm 10.1$ years] were included in this study. Baseline characteristics are shown in Table 1. The median duration of AF was 36 months (IQR 34). Atrial fibrillation was paroxysmal in 43 patients (52\%), persistent in 38 patients (46\%) and longstanding persistent in 2 patients $(2 \%)$, according to current guidelines definitions. ${ }^{12}$ In 73 patients (87\%) ablation was performed using a radiofrequency catheter and in 10 patients (12\%) using a cryoballoon catheter. The procedural endpoint of pulmonary vein isolation was reached in all patients. No major procedural complications were observed, while minor complications occurred in 5 patients (Table 1).

\section{LA volume, sphericity and fibrotic content}

The median LA volume on CMR was $94.4 \mathrm{ml}$ (IQR 43.8), mean LA sphericity was $79.2 \pm 3.2$ and median LA fibrotic content was $6.2 \mathrm{~cm}^{2}$ (IQR 8.9), corresponding to a median $6.0 \%$ (IQR 6.7) of the LA surface.

The LA volume was significantly higher in patients with non-paroxysmal AF versus paroxysmal AF (105.6 [IQR 51.4] versus $86.5 \mathrm{ml}$ [IQR 37.5], p=0.001). The LA sphericity was similar between patients with non-paroxysmal and paroxysmal AF $(79.4 \pm 3.5$ versus 
$79.0 \pm 3.0, p=0.550)$. The absolute amount of LA fibrotic content was higher in patients with non-paroxysmal AF compared to paroxysmal AF $\left(8.4 \mathrm{~cm}^{2}\right.$ [IQR 9.1$]$ versus $5.0 \mathrm{~cm}^{2}$ [IQR 6.8], $p=0.039$ ), but the percentage of LA fibrosis relative to the LA surface was not significantly different (6.8\% [IQR 8.0] in non-paroxysmal versus 5.7\% [IQR 5.2] in paroxysmal, $p=0.264)$. There was an intermediate correlation between LA volume and LA sphericity $(R=0.535, p<0.001$, Figure 2, panel A). Furthermore, a weak but significant correlation was found between LA volume and LA fibrotic content $(R=0.241, p=0.029$, Figure 2, panel B).

\section{Follow-up after catheter ablation}

After a follow-up of 12 month, 60 patients $(72 \%)$ had maintained stable sinus rhythm after a mean of $1.3 \pm 0.6$ procedures. The success rate after one ablation procedure was $57 \%$. At 12 months of follow-up, antiarrhythmic drugs had been discontinued in 48 patients (80\%) with stable sinus rhythm. There was no difference in the recurrence rate between radiofrequency catheter ablation and cryoballoon ablation (30\% versus $10 \%$, respectively, $p=0.182$ ). Moreover, there was no significant difference in recurrence rate between patients without additional ablation lesions, patients with additional linear lesions and patients with both additional linear lesions as well as CFAE (23\% versus $37 \%$ versus $38 \%$, respectively, $\mathrm{p}=0.419$ ). Univariable Cox regression analyses (Table 2 ) showed that LA volume was significant predictor of AF recurrence after ablation (HR 1.024, $p<0.001)$. Furthermore, LA sphericity had a significant prognostic impact on the efficacy of catheter ablation (HR 1.187, $p=0.030$ ). There was no significant relation between the absolute amount of LA fibrosis and AF recurrence (HR 1.026, $p=0.210)$. However, there was a tendency towards a higher risk for AF recurrence in patients with UTAH IV stage LA fibrosis (HR 4.015, $p=0.062$ ). Non- 
paroxysmal AF was associated with a higher risk for AF recurrence (HR 3.006, $p=0.016)$. No other parameters predicted AF recurrence.

Multivariate analyses demonstrated that that LA volume was the strongest and only independent predictor of AF recurrence after catheter ablation (Table 3). ROC analyses demonstrated that the optimal cut-off value for LA volume to predict AF recurrence was 93.0 $\mathrm{ml}$ : area under the curve of $0.680(p=0.013)$, sensitivity of 0.70 , specificity of 0.57 , positive predictive value of 0.38 and negative predictive value of 0.83 (Figure 3 ).

\section{DISCUSSION}

The present study investigated the impact of LA volume, sphericity and fibrotic content on the outcome of catheter ablation for AF. Our results demonstrate that these LA remodelling markers are closely associated with each other. The most important finding of this study is that, despite this close association, LA volume is the strongest independent predictor of AF recurrence after catheter ablation.

\section{Left atrial structural remodelling}

Left atrial remodelling is a complex process of structural and electrical changes that determines the susceptibility of the heart to develop and perpetuate AF. ${ }^{13,14} \mathrm{~A}$ higher extent of LA remodelling limits the efficacy of catheter ablation for $A F{ }^{3,4}$ Therefore, markers of LA remodelling have been used to predict the outcome of catheter ablation for AF by different groups. $^{4,5}$

Left atrial dilatation is one of the hallmarks of LA remodelling and has been long since recognized as a predictor of AF recurrence after catheter ablation. More recently, LA sphericity and LA fibrosis were reported to yield additive information leading to a more 
comprehensive assessment of LA remodelling and eventually improvement of the prediction of $\mathrm{AF}$ recurrence after ablation. ${ }^{7,9}$

The present study demonstrated that there is a clear association between LA volume, LA sphericity and LA fibrosis: a higher extent of LA dilatation is related to a more sphere-shaped LA with a higher degree of fibrosis. Nevertheless, these associations are of a weak to moderate intensity, suggesting that to a certain extent they reflect different processes contributing to atrial remodelling. This is in agreement with computational models that demonstrated that both atrial dilation and fibrotic content independently contribute to structural remodelling of the atria and the incidence of AF. ${ }^{15,16}$ Atrial morphology as a sign of remodelling has also been studied, ${ }^{17}$ but clear proof of a direct arrhythmogenic effect is still lacking.

Currently it is unclear whether LA volume, LA sphericity and LA fibrotic content follow a linear relationship during the process of atrial remodeling. There are suggestions that this might not be the case. ${ }^{18}$ In agreement with these findings, the current population contained a subgroup of patients with a remarkable high degree of LA fibrosis in the presence of nonor mildly dilated atria (Figure 2B). Our results demonstrate that LA volume was a stronger predictor of AF recurrence after catheter ablation than LA sphericity and LA fibrosis. To our knowledge, this is the first time that the relation between these markers of LA remodelling is studied, as well as their relative impact on the outcome of catheter ablation for AF.

Previous work by Bisbal et al also demonstrated that there is a relation between LA dilatation and LA sphericity. ${ }^{7}$ Different to our study, they found that LA sphericity was a stronger predictor of AF recurrence than LA volume. However, in their study the mean LA volume was considerably smaller than in the present study $(81.8 \pm 26 \mathrm{ml}$ versus $94.4 \mathrm{ml}$ [IQR $43.8 \mathrm{ml}]$ ), likely reflecting AF patients at an earlier stage and with less remodelled atria. 
These results suggest that LA sphericity has an important prognostic impact only in moderately diseased atria, whereas LA volume is more important in patients with a more advanced stage of atrial disease.

In contrast, Marrouche et al. demonstrated that LA fibrosis only limits the efficacy of catheter ablation for AF in patients with a severely diseased LA with a high degree of fibrotic content (UTAH IV) but not in patients with an intermediate or low degree of LA fibrosis. ${ }^{9}$ In the present study, only 3 patients (4\%) demonstrated a UTAH IV degree of LA fibrosis. The low prevalence of a high amount of fibrosis in the present population could be an explanation why the amount of LA fibrotic content failed to reach statistical significance.

\section{Limitations}

The current study represents a consecutive group of patients who underwent CE-CMR prior to a catheter ablation for AF, when CE-CMR was available. Additional research should be performed to confirm these results. Moreover, there could be a different prognostic impact of LA volume, LA sphericity and LA fibrotic content on the outcome of AF ablation in patients with relatively less remodelled atria than in severely diseased atria. Since the prevalence of severely diseased atria with a high degree of fibrosis (UTAH IV) is relatively low, the current study is most likely underpowered to demonstrate the prognostic impact of fibrotic content on the outcome of AF ablation. Therefore, further studies should be performed in patients with different stages of atrial disease before drawing final conclusions. Furthermore, the detection of AF recurrence after catheter ablation was based on Holter registrations acquired on a systematic basis. Importantly, patients were encouraged to obtain an ECG registration when experiencing palpitations in order to confirm AF as the cause of these complaints. Nevertheless, asymptomatic episodes may have been missed. 


\section{Conclusion}

Left atrial volume, LA sphericity and LA fibrotic content are closely related. However, LA volume is the strongest independent predictor of AF recurrence after catheter ablation.

\section{REFERENCES}

1. Calkins H, Kuck KH, Cappato R, Brugada J, Camm AJ, Chen SA, Crijns HJ, Damiano RJ, Jr., Davies DW, DiMarco J, Edgerton J, Ellenbogen K, Ezekowitz MD, Haines DE, Haissaguerre M, Hindricks G, lesaka Y, Jackman W, Jalife J, Jais P, Kalman J, Keane D, Kim YH, Kirchhof P, Klein G, Kottkamp H, Kumagai K, Lindsay BD, Mansour M, Marchlinski FE, McCarthy PM, Mont JL, Morady F, Nademanee K, Nakagawa H, Natale A, Nattel S, Packer DL, Pappone C, Prystowsky E, Raviele A, Reddy V, Ruskin JN, Shemin RJ, Tsao HM and Wilber D. 2012 HRS/EHRA/ECAS Expert Consensus Statement on Catheter and Surgical Ablation of Atrial Fibrillation: recommendations for patient selection, procedural techniques, patient management and follow-up, definitions, endpoints, and research trial design. Europace : European pacing, arrhythmias, and cardiac electrophysiology : journal of the working groups on cardiac pacing, arrhythmias, and cardiac cellular electrophysiology of the European Society of Cardiology. 2012;14:528-606.

\section{Verma A, Champagne J, Sapp J, Essebag V, Novak P, Skanes A, Morillo CA,} Khaykin $\mathrm{Y}$ and Birnie D. Discerning the incidence of symptomatic and asymptomatic episodes of atrial fibrillation before and after catheter ablation (DISCERN AF): a prospective, multicenter study. JAMA internal medicine. 2013;173:149-56.

3. Verma A, Wazni OM, Marrouche NF, Martin DO, Kilicaslan F, Minor S, Schweikert RA, Saliba W, Cummings J, Burkhardt JD, Bhargava M, Belden WA, Abdul-Karim A and Natale A. Pre-existent left atrial scarring in patients undergoing pulmonary vein antrum 
isolation: an independent predictor of procedural failure. Journal of the American College of Cardiology. 2005;45:285-92.

4. den Uijl DW, Gawrysiak M, Tops LF, Trines SA, Zeppenfeld K, Schalij MJ, Bax JJ and Delgado V. Prognostic value of total atrial conduction time estimated with tissue Doppler imaging to predict the recurrence of atrial fibrillation after radiofrequency catheter ablation. Europace : European pacing, arrhythmias, and cardiac electrophysiology : journal of the working groups on cardiac pacing, arrhythmias, and cardiac cellular electrophysiology of the European Society of Cardiology. 2011;13:1533-40.

5. Berruezo A, Tamborero D, Mont L, Benito B, Tolosana JM, Sitges M, Vidal B, Arriagada G, Mendez F, Matiello M, Molina I and Brugada J. Pre-procedural predictors of atrial fibrillation recurrence after circumferential pulmonary vein ablation. European heart journal. 2007;28:836-41.

6. den Uijl DW and Bax JJ. Left atrial size as a predictor of successful radiofrequency catheter ablation for atrial fibrillation. Europace : European pacing, arrhythmias, and cardiac electrophysiology : journal of the working groups on cardiac pacing, arrhythmias, and cardiac cellular electrophysiology of the European Society of Cardiology. 2009;11:1255-6.

7. Bisbal F, Guiu E, Calvo N, Marin D, Berruezo A, Arbelo E, Ortiz-Perez J, de Caralt TM, Tolosana JM, Borras R, Sitges M, Brugada J and Mont L. Left atrial sphericity: a new method to assess atrial remodeling. Impact on the outcome of atrial fibrillation ablation. $J$ Cardiovasc Electrophysiol 2013;24:752-9.

8. Benito EM, Carlosena-Remirez A, Guasch E, Prat-Gonzalez S, Perea RJ, Figueras R, Borras R, Andreu D, Arbelo E, Tolosana JM, Bisbal F, Brugada J, Berruezo A and Mont L. Left atrial fibrosis quantification by late gadolinium-enhanced magnetic resonance: a new 
method to standardize the thresholds for reproducibility. Europace : European pacing, arrhythmias, and cardiac electrophysiology : journal of the working groups on cardiac pacing, arrhythmias, and cardiac cellular electrophysiology of the European Society of Cardiology. 2016.

9. McGann C, Akoum N, Patel A, Kholmovski E, Revelo P, Damal K, Wilson B, Cates J, Harrison A, Ranjan R, Burgon NS, Greene T, Kim D, Dibella EV, Parker D, Macleod RS and Marrouche NF. Atrial fibrillation ablation outcome is predicted by left atrial remodeling on MRI. Circulation Arrhythmia and electrophysiology. 2014;7:23-30.

10. Bisbal F, Gomez-Pulido F, Cabanas-Grandio P, Akoum N, Calvo M, Andreu D, PratGonzalez S, Perea RJ, Villuendas R, Berruezo A, Sitges M, Bayes-Genis A, Brugada J, Marrouche NF and Mont L. Left Atrial Geometry Improves Risk Prediction of Thromboembolic Events in Patients With Atrial Fibrillation. J Cardiovasc Electrophysiol 2016;27:804-10.

11. Kuck KH, Brugada J, Furnkranz A, Metzner A, Ouyang F, Chun KR, Elvan A, Arentz T, Bestehorn K, Pocock SJ, Albenque JP and Tondo C. Cryoballoon or Radiofrequency Ablation for Paroxysmal Atrial Fibrillation. The New England journal of medicine. 2016;374:2235-45.

12. Kirchhof P, Benussi S, Kotecha D, Ahlsson A, Atar D, Casadei B, Castella M, Diener HC, Heidbuchel H, Hendriks J, Hindricks G, Manolis AS, Oldgren J, Popescu BA, Schotten U, Van Putte B, Vardas P, Agewall S, Camm J, Baron Esquivias G, Budts W, Carerj S, Casselman F, Coca A, De Caterina R, Deftereos S, Dobrev D, Ferro JM, Filippatos G, Fitzsimons D, Gorenek B, Guenoun M, Hohnloser SH, Kolh P, Lip GY, Manolis A, McMurray J, Ponikowski P, Rosenhek R, Ruschitzka F, Savelieva I, Sharma S, Suwalski P, Tamargo 
JL, Taylor CJ, Van Gelder IC, Voors AA, Windecker S, Zamorano JL and Zeppenfeld K. 2016 ESC Guidelines for the management of atrial fibrillation developed in collaboration with EACTS. Europace : European pacing, arrhythmias, and cardiac electrophysiology : journal of the working groups on cardiac pacing, arrhythmias, and cardiac cellular electrophysiology of the European Society of Cardiology. 2016;18:1609-1678.

13. Wijffels MC, Kirchhof CJ, Dorland R and Allessie MA. Atrial fibrillation begets atrial fibrillation. A study in awake chronically instrumented goats. Circulation. 1995;92:1954-68.

14. Ausma J, Litjens N, Lenders MH, Duimel H, Mast F, Wouters L, Ramaekers F, Allessie $\mathrm{M}$ and Borgers $\mathrm{M}$. Time course of atrial fibrillation-induced cellular structural remodeling in atria of the goat. Journal of molecular and cellular cardiology. 2001;33:208394.

15. Verheule S, Eckstein J, Linz D, Maesen B, Bidar E, Gharaviri A and Schotten U. Role of endo-epicardial dissociation of electrical activity and transmural conduction in the development of persistent atrial fibrillation. Progress in biophysics and molecular biology. $2014 ; 115: 173-85$

16. Zou R, Kneller J, Leon LJ and Nattel S. Substrate size as a determinant of fibrillatory activity maintenance in a mathematical model of canine atrium. American journal of physiology Heart and circulatory physiology. 2005;289:H1002-12.

17. Cates J, Bieging E, Morris A, Gardner G, Akoum N, Kholmovski E, Marrouche N, McGann C and MacLeod RS. Computational Shape Models Characterize Shape Change of the Left Atrium in Atrial Fibrillation. Clinical Medicine Insights Cardiology. 2014;8:99-109. 
18. den Uijl DW, Delgado V, Bertini M, Tops LF, Trines SA, van de Veire NR, Zeppenfeld K, Schalij MJ and Bax JJ. Impact of left atrial fibrosis and left atrial size on the outcome of catheter ablation for atrial fibrillation. Heart (British Cardiac Society). 2011;97:1847-51.

\section{TABLES}

Table 1. Baseline

\begin{tabular}{|c|c|}
\hline Baseline characteristics & Population $(n=83)$ \\
\hline Age (years) & $55.8 \pm 10.1$ \\
\hline Male gender, $\mathrm{n}(\%)$ & $64(77 \%)$ \\
\hline Body surface area $\left(\mathrm{m}^{2}\right)$ & $2.00 \pm 0.21$ \\
\hline Duration of $\mathrm{AF}$ (months) & 36 (IQR 34) \\
\hline Non-paroxysmal AF, n (\%) & $40(48 \%)$ \\
\hline Hypertension, n (\%) & $44(53 \%)$ \\
\hline Obstructive sleep apnea syndrome, n (\%) & $11(13 \%)$ \\
\hline LA anterior-posterior diameter (mm) & $42.8 \pm 5.2$ \\
\hline LA volume (ml) & 94.4 (IQR 43.8) \\
\hline Left ventricular ejection fraction (\%) & $58.6 \pm 7.4$ \\
\hline LA sphericity & $79.2 \pm 3.2$ \\
\hline LA fibrotic content $\left(\mathrm{cm}^{2}\right)$ & 6.2 (IQR 8.9) \\
\hline
\end{tabular}

This article is protected by copyright. All rights reserved. 


\begin{tabular}{|c|c|}
\hline LA fibrotic content classification & \\
\hline - UTAH I (<5\% of LA surface), $n(\%)$ & $31(37 \%)$ \\
\hline - UTAH II (5-20\% of LA surface), $n$ (\%) & $46(55 \%)$ \\
\hline - UTAH III (20-35\% of LA surface), $n$ (\%) & $3(4 \%)$ \\
\hline - UTAH IV (>35\% of LA surface), $n(\%)$ & $3(4 \%)$ \\
\hline Failed antiarrhythmic drugs & \\
\hline Class IC antiarrhythmic drug, $\mathrm{n}(\%)$ & $46(55 \%)$ \\
\hline Amiodarone, $\mathrm{n}(\%)$ & $37(45 \%)$ \\
\hline Sotalol, n (\%) & $6(7 \%)$ \\
\hline Procedural characteristics & \\
\hline Radiofrequency, n (\%) & $73(88 \%)$ \\
\hline Cryoballoon, n (\%) & $10(12 \%)$ \\
\hline Additional lesions, $\mathrm{n}(\%)$ & $27(33 \%)$ \\
\hline - Linear lines, $n(\%)$ & $19(23 \%)$ \\
\hline - Linear lesions and CFAE, n (\%) & $8(10 \%)$ \\
\hline
\end{tabular}

This article is protected by copyright. All rights reserved. 


\begin{tabular}{|c|c|}
\hline Complications & \\
\hline - Pericarditis, n (\%) & $1(1 \%)$ \\
\hline - Femoral hematoma, n (\%) & $2(2 \%)$ \\
\hline - Femoral pseudoaneurysm, n (\%) & $3(4 \%)$ \\
\hline - Femoral arteriovenous fistula, n (\%) & $1(1 \%)$ \\
\hline
\end{tabular}

Table 2. Cox univariable proportional hazard analyses of clinical and magnetic resonance imaging characteristic to predict AF recurrence after catheter ablation

\begin{tabular}{|l|l|c|c|}
\hline & HR & $\mathbf{9 5 \%}$ Cl & $P$-value \\
\hline Age, per year & 1.009 & $0.966-1.055$ & 0.674 \\
\hline Male gender & & & \\
\hline Body surface area, per m ${ }^{2}$ & 0.804 & $0.317-2.039$ & 0.645 \\
\hline Duration of AF, per month & 1.112 & $0.138-8.982$ & 0.921 \\
\hline Non-paroxysmal AF & & & 0.531 \\
\hline Hypertension & 1.004 & $0.992-1.016$ & \\
\hline LA volume, per ml & 3.006 & $1.233-7.328$ & 0.016 \\
& & & 0.423 \\
\hline
\end{tabular}

This article is protected by copyright. All rights reserved. 


\begin{tabular}{|l|l|l|c|}
\hline LA sphericity, per unit & 1.187 & $1.017-1.385$ & 0.030 \\
\cline { 2 - 5 } & LA fibrotic content & & \\
\hline \\
\cline { 1 - 4 } \\
\hline
\end{tabular}

Table 3. Cox multivariable proportional hazard analyses of clinical and magnetic resonance imaging characteristic to predict AF recurrence after catheter ablation.

\begin{tabular}{|l|c|c|c|c|c|c|c|}
\hline & \multicolumn{2}{|c|}{ Step 1 } & \multicolumn{2}{c|}{ Step 2 } & \multicolumn{2}{c|}{ Step 3 } \\
\cline { 2 - 8 } & & HR & $P$-value & HR & $P$-value & HR & $P$-value \\
\cline { 2 - 8 } & Non-paroxysmal AF & 2.325 & 0.115 & 2.158 & 1.141 & 2.327 & 0.101 \\
\hline & & & & & & & 0.018 \\
\hline
\end{tabular}

\section{FIGURE LEGENDS}

Figure 1. After acquisition, all CE-CMR data were exported to the ADAS $®$ program for offline post-processing (panel A). After semi-automatic tracing of the endocardial and epicardial contours, the system constructed a mid-myocardial layer in which it calculated the signal 
Panel A.

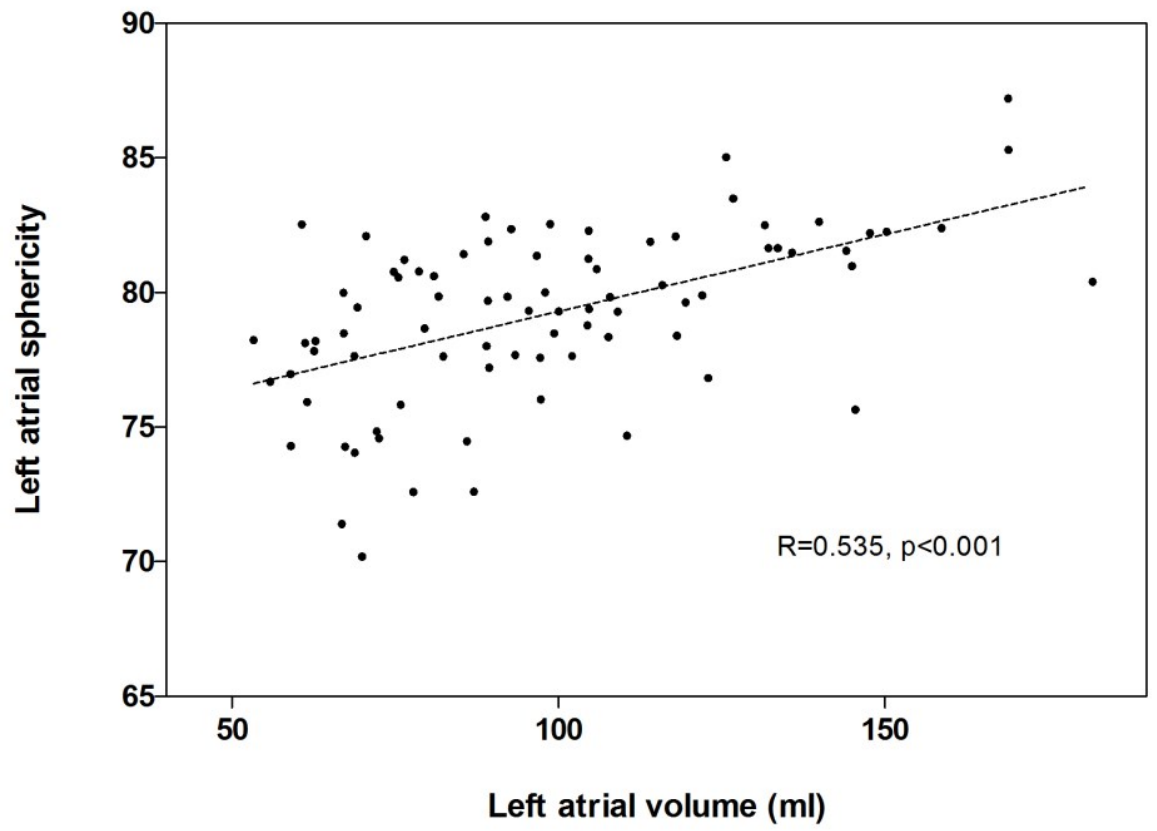

Panel B.

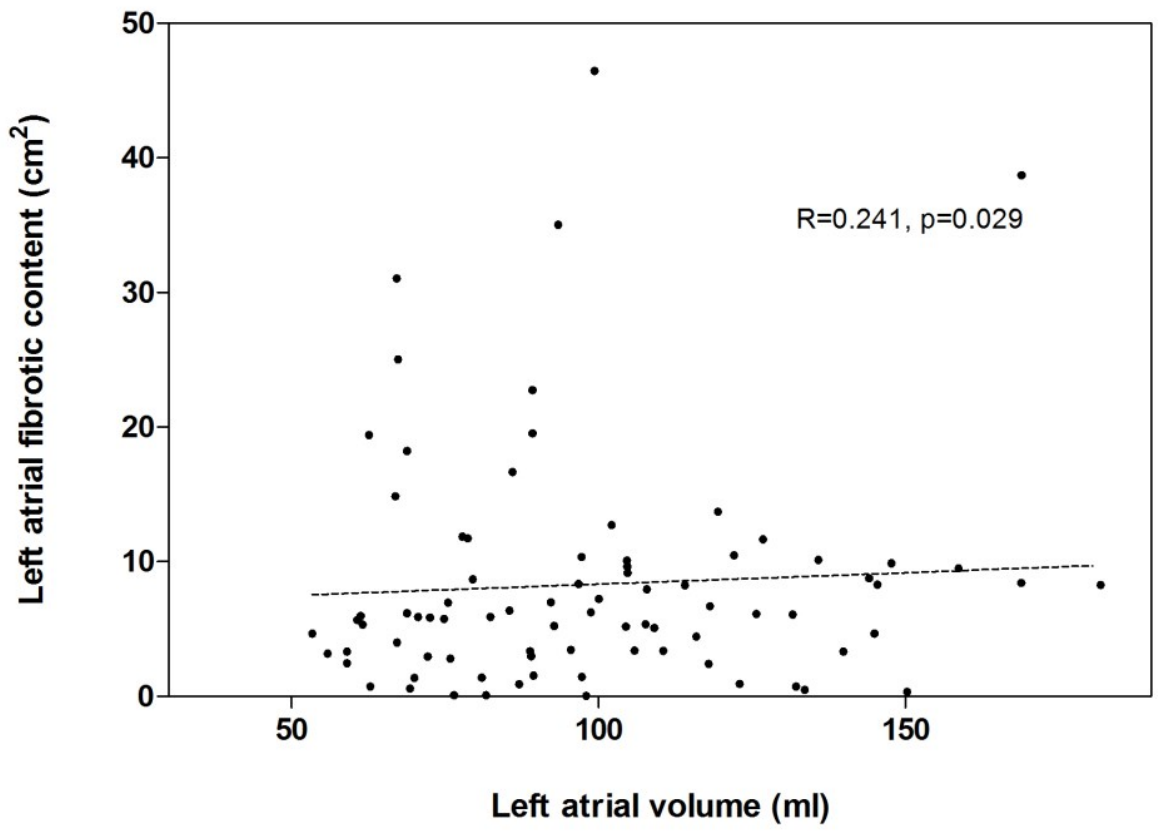

This article is protected by copyright. All rights reserved. 
Figure 3. Kaplan-Meier curve for freedom of atrial fibrillation (AF) after catheter ablation according to left atrial volume $<93.0 \mathrm{ml}$ or $\geq 93.0 \mathrm{ml}$.

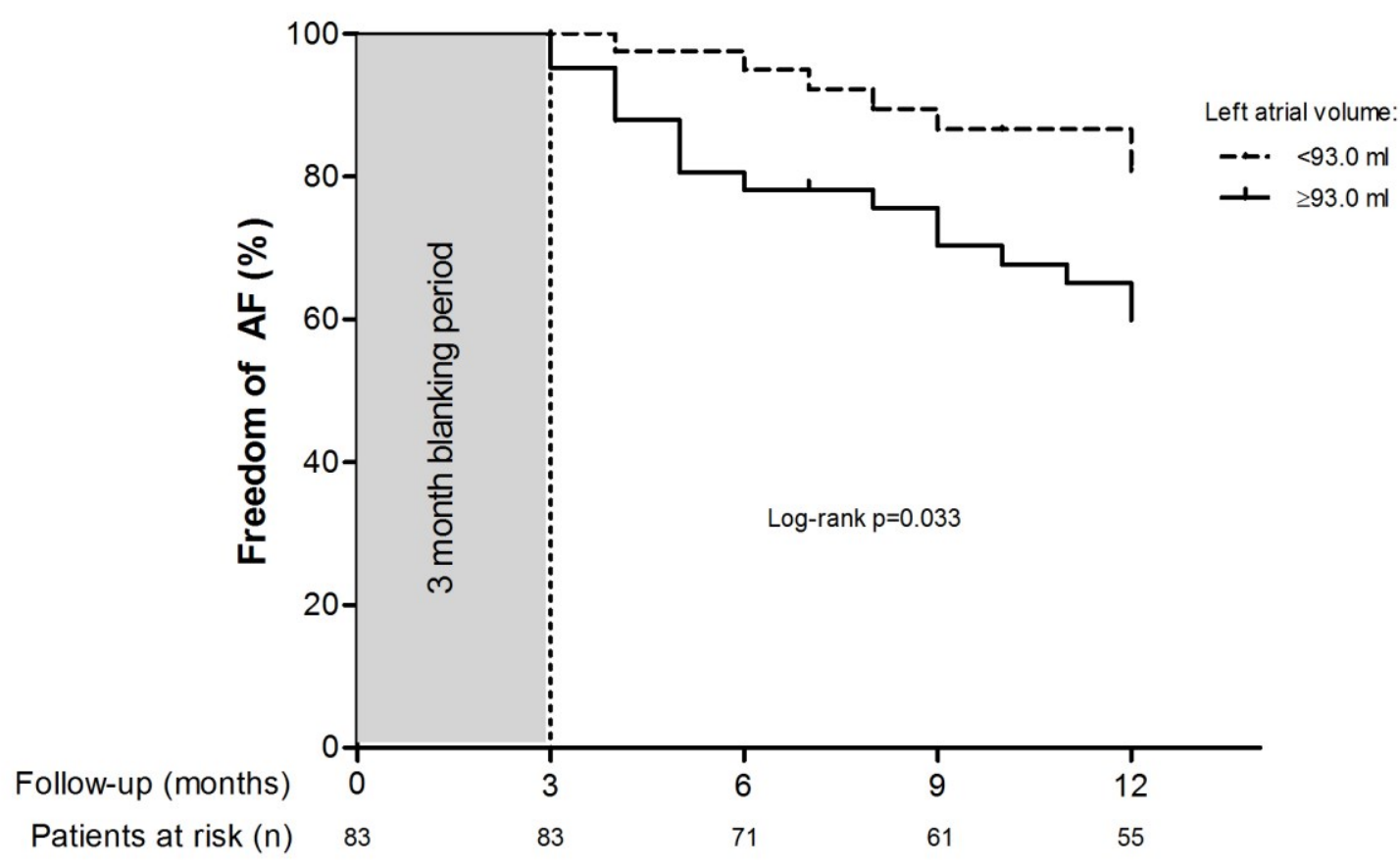

This article is protected by copyright. All rights reserved. 